\title{
Culto evangélico: identificación, localización y caracterización en la tercera y cuarta franja residencial (TFR y CFR) de Río Gallegos
}

\section{Evangelical worship: identification, localization and characterization in Río Gallegos' third and fourth residential strip (TRS and FRS)}

\author{
Federico A. Huenchor, Mónica V. Norambuena, Alicia P. Cáceres \\ fedde.h29@gmail.com,mnorambuena@uarg.unpa.edu.ar, acaceres@uarg.unpa.edu.ar \\ Grupo Z Terra Cognita \\ Instituto de Ciencias del Ambiente, Sustentabilidad y Recursos Naturales Unidad Académica \\ Río Gallegos, Universidad Nacional de la Patagonia Austral \\ Piloto Lero Rivero y Avenida Gobernador Gregores - Río Gallegos - Santa Cruz - Argentina
}

Recibido: 30/04/2021. Aceptado: 13/07/2021

\section{RESUMEN}

El presente Informe Científico-Técnico, pertenece a una Beca de Investigación para Alumnos Avanzados de la UNPA y se enmarca en el PI 29/A427-1 "La Geografía de las Religiones en el ejido municipal de Río Gallegos en el año 2018. La Geografía Cultural en la Patagonia austral extraandina”. Teóricamente, pertenece a la Geografía cultural renovada en general y en particular a la Geografía de las Religiones, históricamente estudiadas desde la descripción y en sus características más básicas; actualmente se estudian integradas al territorio y sus transformaciones a diferentes escalas. Son escasas las investigaciones relacionadas a Río Gallegos, por tal motivo, este informe tiene como objetivos, en primer lugar, relevar y analizar bibliografía específica sobre la Geografía cultural y la Geografía de las religiones en particular. En segundo lugar, identificar, caracterizar y cartografiar manifestaciones culturales religiosas relacionadas al culto evangélico en la Tercera y Cuarta Franja Residencial de Río Gallegos. Metodológicamente, se relevó, leyó comprensivamente y analizó bibliografía específica; se planificó una salida de campo para identificar y localizar las manifestaciones culturales religiosas evangélicas en la TFR y CFR, la que se suspendió y se realizó un reajuste metodológico; las manifestaciones identificadas y localizadas fueron representadas cartográficamente a través de un SIG. Los resultados permitirán caracterizar las manifestaciones culturales, según las denominaciones de las iglesias evangélicas, además de aportar teórica y metodológicamente al PI 29/A427-1 y a la formación en investigación del becario

Palabras clave: Patagonia austral; Geografía de las religiones; cristianismo; ejido municipal; siglo XXI.

\begin{abstract}
This report, itself an investigation scholarship directed to UNPA's advanced students, belongs to IP 29/A427-1 'Religious geography in Río Gallegos' municipal land during 2018. Cultural geography in southern extra-Andean Patagonia'. Theoretically, it belongs to the Renewed Cultural Geography in general, and to the Religious Geography in particular, which historically speaking has been studied in a descriptive sense and in its most basic characteristics; nowadays they are being studied in relation to territory and to the
\end{abstract}


transformations taking place at different scales. Investigations related to Río Gallegos are scarce, hence, it's first purpose is to gather and analyze literature related to Cultural Geography and Religious Geography; and it's second purpose is to identify, characterize and to create cartography about the evangelical cultural manifestations taking place inside Río Gallegos' Third Residential Strip and Fourth Residential Strip. In relation to this work's methodology, specific literature was read and analyzed thoroughly, also, a field trip was planned to take place in order to identify and localize the evangelical religious and cultural manifestations inside the aforementioned residential strips, but said field trip had to be cancelled, meaning a methodological adjustment had to be done; the religious manifestations that were identified and localized, were later mapped through a GIS to create a thematic map. These results will make it possible to characterize such manifestations according to each evangelical church denomination, such actions will provide scientific and methodological knowledge to the IP 29/A427-1 and to the student's formation in research.

Keywords: Southern Patagonia; religion; Christianism; municipal land; XXI century.

\section{INTRODUCCIÓN}

La Geografía cultural, ha tenido escaso desarrollo dentro de la Geografía. Actualmente, se realizan investigaciones enmarcadas en la geografía cultural renovada. Este es el caso de las religiones, históricamente estudiadas desde la descripción y en sus características más básicas, para hoy estudiar su influencia en la identidad territorial a distintas escalas. Hay una nueva mirada de la Geografía de las religiones como enfoque emergente vinculado a la renovada Geografía cultural, que aporta nuevos conceptos y categorías de análisis (Santarelli y Campos, 2011:2). Son escasos los trabajos relacionados a Río Gallegos, ciudad intermedia de la Patagonia austral extraandina.

Por tanto, el tema central de la presente Beca de Iniciación a la Investigación de un Alumno Avanzado de la UNPA en la Licenciatura en Geografía y su finalidad, es el estudio del culto evangélico en la ciudad de Río Gallegos, para la identificación, localización y caracterización en la Tercera Franja Residencial (TFR) y Cuarta Franja Residencial (CFR).

Se plantearon dos objetivos, el primero es relevar y analizar bibliografía específica sobre la Geografía cultural y la Geografía de las religiones en particular; el segundo es identificar, caracterizar y cartografiar manifestaciones culturales religiosas relacionadas al culto evangélico en la TFR y la CFR de Río Gallegos. Metodológicamente, se trata de una investigación exploratoria y descriptiva, ya que describe y caracteriza a los templos evangélicos de la TFR y CFR.

En referencia al culto evangélico en Río Gallegos, el artículo "Núcleo formativo del campo evangélico: heterogeneidad identitaria en Río Gallegos (Santa Cruz) hacia fines de 1950" de Héctor Mancilla (2009), es la base histórica sobre esta religión. Antecedentes de la Geografía de las religiones en Río Gallegos son, el trabajo de Alicia P. Cáceres (2011), "Distribución espacial de los edificios religiosos, según áreas de la estructura interna de Río Gallegos" y el de Cristian Ampuero (2011), "La veneración del Nazareno de Caguach en la ciudad de Río Gallegos, Patagonia austral argentina". También se puede mencionar el trabajo "Culto evangélico: identificación, localización y caracterización en la Segunda Franja Residencial (SFR) de Río Gallegos", del año 2020, de los autores Federico A. Huenchor, Mónica V. Norambuena, y Alicia P. Cáceres. 
La hipótesis es: las manifestaciones culturales religiosas relacionadas al culto evangélico, se pueden identificar, localizar y caracterizar en la TFR y CFR de Río Gallegos, por tanto, es posible estudiar estos fenómenos culturales en el marco de la Geografía de las religiones.

Metodológicamente, se recurrió a la búsqueda y lectura comprensiva para seleccionar bibliografía específica. Para el relevamiento de los templos evangélicos, se confeccionó una planilla de cálculo en Excel, en la cual se tuvieron en cuenta las características más relevantes de los mismos. Se programó una salida de campo, a fin de realizar observación directa, pero tuvo que ser cancelada debido a las medidas implementadas por los gobiernos nacional (DECNU $\mathrm{N}^{\circ}$ 260/2020- modificado por Decreto $\mathrm{N}^{\circ}$ 287/2020-APN-PTE Disposiciones), provincial (Decreto $\mathrm{N}^{\circ}$ 0273/2020 Ejecutivo Provincia de Santa Cruz) y municipal (Decreto N 891/20 Ejecutivo Municipal Ad Referéndum del HCD Río Gallegos) debido a la pandemia causada por el virus SARS-CoV-2; lo que llevó a realizar un ajuste metodológico y reemplazar la observación directa por la indirecta, a través del uso de programas informáticos como Google Earth y Google Maps. Asimismo, se llevaron a cabo recorridos informales en el área de estudio, a fin de corroborar información relevada y obtener un registro fotográfico de los templos evangélicos. Por último, se utilizó el programa Qgis Hannover para la confección de los mapas temáticos y se redactaron dos informes, uno científico para ser presentado en

formato ICT y otro de divulgación para la Municipalidad de Río Gallegos, además del informe de desempeño del becario.

Con esta investigación se espera aportar al conocimiento científico y a la metodología de estudio relacionada a la Geografía cultural y de la Geografía de las religiones en relación con la ciudad de Río Gallegos. Igualmente, conocer la dinámica que poseen las denominaciones evangélicas en la TFR y CFR.

\section{MARCO DE REFERENCIA}

\section{Marco histórico-geográfico}

\section{GEOGRAFÍA DEL EJIDO MUNICIPAL DE RÍO GALLEGOS}

La Provincia de Santa Cruz, por las dispares distancias geográficas entre las localidades, ha establecido un modelo de gestión municipal diferenciado con respecto a otras provincias del país. La unidad social y política del municipio corresponde al modelo "Municipio-Localidad" (Cáceres, 2000:868), cuya base territorial se denomina ejido urbano. Los límites espaciales se fijan a priori por el perímetro de operatividad del municipio y de un límite en el espacio jurídico por la existencia de reglamentaciones particulares que dan paso a especulaciones inmobiliarias dentro y fuera del mismo (Cáceres et al, 1999:116 en Cáceres et al, 2017:62). El ejido municipal comprende una superficie aproximada de 10.000 hectáreas donde residen, según proyección en el año 2015 unos 105.047 habitantes.

Río Gallegos es la ciudad capital de la Provincia de Santa Cruz, la más austral de la Patagonia Continental Argentina, se sitúa al SE de la provincia, del país y de la región, su posición es austral, extrema y periférica. En la ciudad se superponen a lo largo de $35 \mathrm{~km}$, las rutas nacionales $\mathrm{N}^{\circ} 3(\mathrm{~km} 2607)$ y $\mathrm{N}^{\circ} 40(\mathrm{~km} \mathrm{135)}$, que definen para Río Gallegos su situación de encrucijada (Cáceres, 1996; 2013). La ruta nacional $N^{\circ} 3$ permite la conexión con el resto del país hacia el norte, al sur hacia la provincia de Tierra del Fuego y hacia el sudoeste con la 
ciudad de Punta Arenas, en la provincia chilena de Magallanes (Fig. 1). Es una ciudad no primada en proceso de metropolización, con equipamiento de servicios e infraestructura suficiente, que la definen como ciudad intermedia (Cáceres et al, 2016:51).

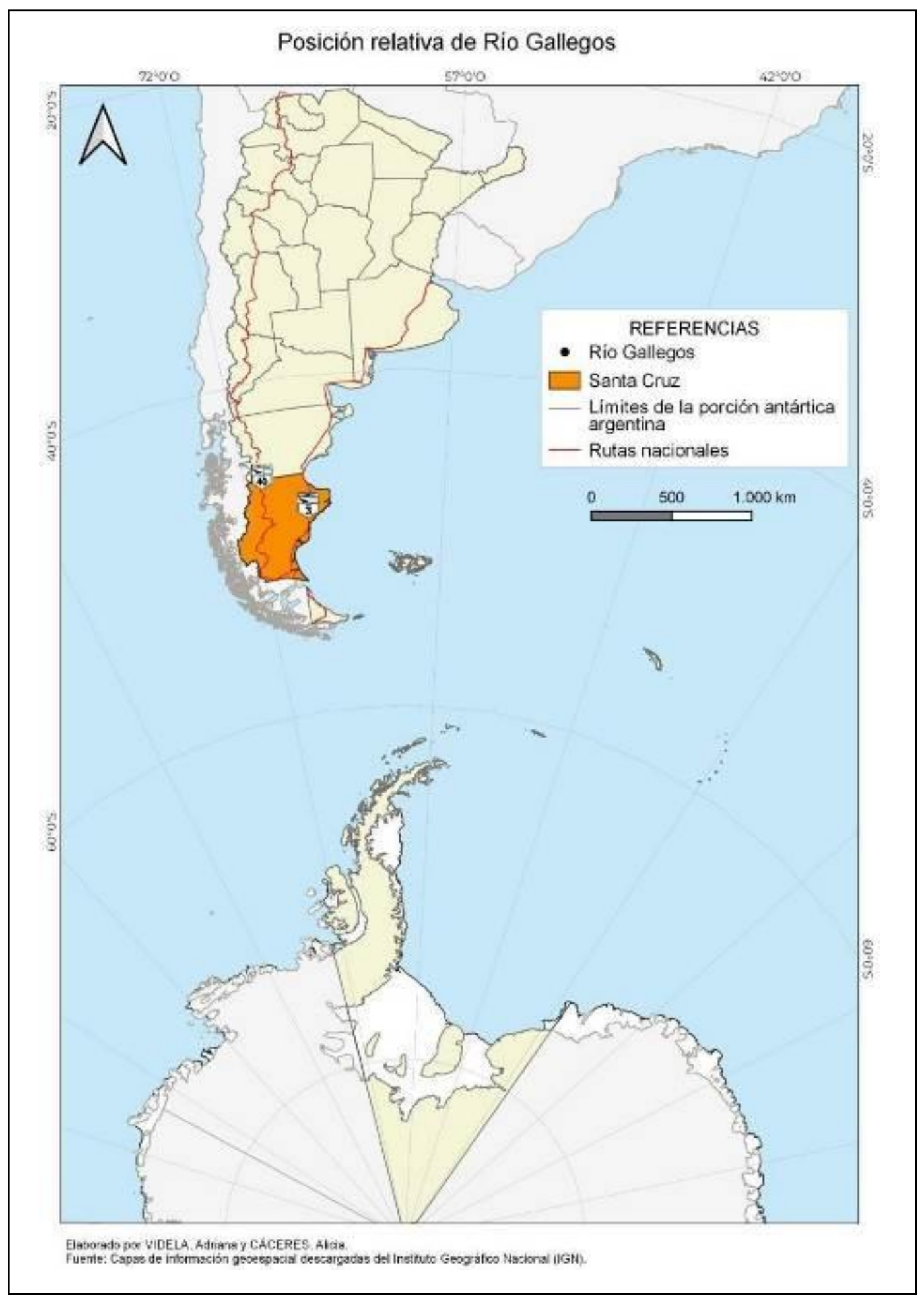

Fig.1. Posición relativa de Río Gallegos. Elaborado por Videla, A. y Cáceres, A.P.

La ciudad de Río Gallegos, está emplazada en la margen sur del estuario del río Gallegos, a 
los 51'37'27" latitud sur y $69^{\circ} 12^{\prime}$ '59" longitud oeste, al sureste de la provincia, siendo esta la más austral de la Patagonia Continental Argentina.

Debido a la latitud, las temperaturas son bajas a lo largo del año, y el régimen de vientos se caracteriza por su frecuencia, intensidad y variación estacional, en invierno (mayo a julio) el promedio es por debajo de los $19 \mathrm{~km} / \mathrm{h}$, mientras que en primavera-verano es por encima de los 26 km/h (Cáceres et al; 2016:53).

\section{Estructura interna del ejido municipal de Río Gallegos}

Cáceres $(2004,2013,2017,2019)$ junto a distintos autores, ha delimitado y actualizado la estructura interna del ejido municipal de Río Gallegos, abordado desde un enfoque integral a partir del análisis de los componentes de la morfología urbana (usos del suelo, tipo de plano, edificación), condicionados por factores de tipo económico, demográfico, político e histórico (Cáceres et al, 2013:48), que permitieron determinar cortes temporales visibles en el paisaje urbano en las distintas etapas de crecimiento de la ciudad.

En el primer trabajo realizado en coautoría con García (2004) al ejido municipal de Río Gallegos, lo dividen en dos grandes áreas: Urbana subdividida en Central (AC), Segunda Franja Residencial (SFR) y Tercera Franja Residencial (TFR); y la Rururbana subdividida en Intraejidal (RI) y Extraejidal (RE).

Describen al AC como el sector histórico, que coincide con la primera traza de la planta urbana realizada entre 1900 y 1924, ocupada principalmente por la migración europea, trazada por los ejes estructuradores de primer orden de la ciudad: Av. Pte. Carlos N. Kirchner y San Martín. Los usos del suelo son variados que le permite cumplir una cantidad de funciones relacionadas con la administración estatal, la concentración de comercios, la localización de servicios comunitarios y culturales, constituye el espacio más dinámico, no sólo del ejido municipal sino también del área de influencia, por tal motivo, es el sector de mayor accesibilidad. El aprovechamiento intensivo en altura del suelo es el de mayor densidad y volumen de edificación en un entramado cerrado y de mayor valor inmobiliario, (alquileres y propiedades). Concentra las principales actividades, la mayoría del equipamiento de la ciudad, y del área de influencia dentro de la red urbana, es así el área de los espacios principales de animación, convivencia, encuentro y de mayor accesibilidad de la ciudad y del área de influencia (Cáceres, 2013:50).

\section{Segunda Franja Residencial}

La SFR de Río Gallegos se extiende a partir de la terminación del AC, durante las décadas del ' 60 y '70 del siglo pasado, estructurada la RN 3/40, las diagonales que empalman con ésta y los intersticios. Corresponde a un segundo momento importante de crecimiento de la población, proveniente de Chile y del resto de Argentina (Cáceres y García; 2004:17).

Morfológicamente, presenta características que la diferencian del resto del ejido municipal, porque se busca el aprovechamiento máximo del suelo, desaparecen los lotes de grandes dimensiones y las calles anchas, se construyen edificios multifamiliares sin ascensores, que resulta en una alta densidad demográfica y volumen de edificación disperso.

El crecimiento y consolidación de la SFR se da hasta finales de la primera década del siglo XXI; la Av. San Martín es el eje estructurador de primer orden de la ciudad, que divide en 
sector occidental y oriental a esta franja. Conforme a la legislación vigente (Municipalidad de Río Gallegos, Ordenanza No 3259 del 2012) para zonificación en la ciudad de Río Gallegos, quedan establecidas las distintas "categorías de uso" reconoce a los edificios religiosos como uso "servicios a la comunidad".

Se localizan barrios construidos por la inmigración chilena (Nuestra Señora del Carmen oeste y Belgrano en el este) "cuya identidad está dada por el estilo arquitectónico de las viviendas con buena adaptación al marco natural” (Cáceres y García; 2004:17).

Barrios para trabajadores de la extracción del carbón, en los distintos momentos de la empresa YCF, luego privatizada en 1994 convertida en Yacimientos Carboníferos Río Turbio SA (YCRT SA), re estatizada en 2002 al Estado nacional, denominada YCRT y en 2010 fue inaugurado el último barrio para propietarios relacionados con esa empresa. El resto del sector, ha sido ocupado por viviendas de construcción particular, con diferentes diseños arquitectónicos, durante el siglo XX, con predominio de la unifamiliar.

Barrios construidos por asociaciones civiles para migrantes argentinos, adosados al eje de expansión; barrios APAP, Provincial, Planeamiento, Gregores e YPF; "barrios planificados por el estado de viviendas uni y multifamiliares Jorge Newbery, Cuatrocientos Departamentos, 366 Viviendas, 499 Viviendas y Centenario, Fátima que, desde la década de 1980, comenzaron a ser compradas por la colectividad gitana, cuyo estilo arquitectónico de casas amplias y de grandes ventanales, combinan con el uso del suelo comercial, rubro venta de automotores. El resto del sector, continúa en proceso de consolidación con viviendas de construcción particular tanto uni como multifamiliares, con diferentes diseños arquitectónicos.

\section{Tercera Franja Residencial (TFR)}

Adosada a la SFR en 2013, Cáceres en coautoría con Norambuena, Ampuero y Triviño estudian sobre la "Consolidación de la tercera franja residencial de Río Gallegos, Patagonia Argentina". El crecimiento urbano de la ciudad estaba frenado por barreras antrópicas, hacia el oeste las vías del FFCC de Yacimientos Carboníferos Fiscales (YCF) además del puerto que no permitía la red de continuidad vial, hacia el sur por el Ejército Argentino y al sureste por la Marina. Fines del siglo XX, políticas públicas como la privatización de Yacimientos Carboníferos Fiscales (YCF.) y de Yacimientos Petrolíferos Fiscales (YPF), el retiro de Fuerzas Armadas como Marina y Fuerza Aérea a finales del siglo XX, han impulsado la expulsión de población (Cáceres et al, 2013:48). De este modo, se recuperan terrenos pertenecientes a las Fuerzas Armadas (Ejército y Armada Argentina) para el uso residencial y educativo respectivamente, el Ramal Ferroindustrial Río Turbio es sustituido por la Av. Ricardo Balbín y el cierre del Muelle Río Turbio del puerto de Río Gallegos permitió la continuidad de la Av. Costanera.

Como resultado de estas transformaciones, los autores determinan sectores diferenciados dentro de la misma franja:

Sector Oeste (TFRO): pertenece a la Circunscripción III, donde no tiene posibilidad de expansión, puesto que sus límites son bordes infranqueables: al norte la margen sur del estuario del Gallegos, al sur la Autovía 17 de octubre, al este la Av. Balbín y Segunda Franja Residencial y al oeste, el límite occidental norte del ejido municipal que limita con el Aeropuerto Internacional Piloto Civil Norberto Fernández.

Cáceres et al en 2013 a esta circunscripción, según la estructura urbana de Río Gallegos, la 
dividen en Tercera Franja Residencial Oeste (TFRO) y Área Rururbana Intraejidal Occidental (ARIO). La TFRO es un sector consolidado adosado a la Av. Balbín, que permite la continuidad en la red de vinculación hacia y desde el AC (Cáceres et al, 2013:56) y la SFRO con la presencia de barrios residenciales Náutico, Vial y Evita. Posee todos los servicios, incluso pavimento y cloacas.

El sector que corresponde al ARIO, en 2011, el municipio de Río Gallegos la definió como primera zona de extensión urbana, se encuentra en un proceso acelerado de consolidación con presencia de usos del suelo como industrial (frigoríficos), de servicios y recreativo. Se caracteriza por "la invasión desorganizada de diferentes usos del suelo" y "por el abandono y subaprovechamiento que predominan en las chacras (unidad económica en el uso rural agrícola de Río Gallegos)" (Cáceres et al, 2011). Es producto de una fuerte especulación inmobiliaria, chacras improductivas fueron subdivididas en loteos de dimensiones urbanas vendidas a particulares, cuya ocupación se lleva a cabo con viviendas de uso permanente principalmente, con entramado abierto y con diseños y materiales de construcción de costo medio-elevado; además, viviendas destinadas al alquiler diario y complejos habitacionales particulares. Cabe aclarar que, no se observan complejos habitacionales construidos por el estado. El uso residencial comparte con otros usos como el industrial con la presencia de frigoríficos, empresas constructoras y de servicios, depósitos comerciales mayoristas, canchas de fútbol al aire libre, complejos para eventos, etc. Los ejes estructuradores centrales son la Av. Francisco Ramírez (N-S)- y en las prolongaciones de importantes ejes de circulación de la ciudad (E-O) -Av. Almirante Brown y Zapiola que se extienden hasta el límite occidental del ejido y hasta $300 \mathrm{~m}$. antes de dicho límite respectivamente).

El ARIO, después de 10 años tiene una alta ocupación del suelo, cuenta con todos los servicios básicos, ahora en proceso de instalación del tendido de cloacas. En el nodo de servicios discontinuo del Barrio Evita (localización de los servicios en manzanas contiguas, González et al, 2018:65), se localizan servicios de Educación (EGB Nº 61/CPEP Nº18), Salud (CenIn 1), Seguridad (Comisaría 6ta.), Comercial (Hipertehuelche, La Anónima y Paralelo Seguridad, Autoservicio Cerca II) y Recreativo (Gimnasio Luis "Lucho" Fernández"). De este modo, Cáceres en 2021 considera que ya no reúne características rururbanas, por tanto, la incorpora a la TFR.

Sector Sur (TFRS): delimitada por las Av. Asturias y San Martín al oeste y este respectivamente, se localizan barrios construidos por el Instituto de Desarrollo Urbano y Vivienda de Santa Cruz (IDUV) en las tierras cedidas por el Ejército y en el extremo sur, el Asentamiento Informal Los Lolos. La Av. Felix Ríquez es el eje estructurador secundario del sector donde se concentran comercios y el uso educativo.

Sector Este (TFRE): delimitada entre la Av. San Martín y la Reserva Costera Urbana, el uso residencial se observa en asentamientos informales sobre tierras de mala calidad. En las tierras cedidas por la Armada Argentina han sido otorgadas a la Universidad Nacional de la Patagonia Austral, quien construyó el Campus Universitario de la Unidad Académica Río Gallegos. Asimismo, Cáceres (2021) incorpora a este sector, el Plan PRO-CRE-AR Bicentenario con una serie de complejos habitacionales que ocupan 15 manzanas de uso residencial. 


\section{Cuarta Franja Residencial (CFR)}

En 2017, Cáceres en coautoría con Norambuena, Frías y Ampuero determinan y delimitan la "Nueva Área Rururbana Intraejidal de Río Gallegos", delimitaron una nueva Rururbana Intraejidal (RI) a partir de cuyos inicios es a partir de la última década del siglo XX, en un área adyacente al límite occidental del ejido municipal con la venta de lotes para el uso residencial, a través de asociaciones gremiales, a precios muy bajos que, por la especulación inmobiliaria dentro del ejido, por la escasez de tierra fiscal, valores elevados en lotes privados y de los alquileres. Esta ocupación extraejidal es sin un previo proyecto de planificación urbana y ordenamiento territorial para usos rururbanos, es acelerada y actúa de disparador del surgimiento de numerosos emprendimientos inmobiliarios, que son incorporados al ejido municipal en dos momentos: 2013 y 2018. La RN 3 en dos tramos, hacia el oeste y hacia el sur, Güer Aike y Chimen Aike respectivamente, el terraplén de las ex vías del tren, el Derivador de Tránsito Pesado (RN 40) y la Av. Asturias, actúan como ejes estructuradores del área.

Cáceres et al en 2017 y Cáceres (2021) identifican y diferencian dos sectores cuyo paisaje urbano del conjunto de barrios, presentan diferencias:

Barrios localizados entre la RN 3 (a Güer Aike) y el terraplén del ex FF.CC. Río Turbio: se identifican los barrios iniciados en el siglo XX con lotes de dimensiones urbanas vendidos por asociaciones gremiales y barrios que surgen en el siglo XXI en proceso incipiente de ocupación, con loteos de entramado abierto, con medianeras de setos vivos y construcciones con diseños y materiales que indican nivel socioeconómico medio alto, con ausencia de equipamiento educativo y de salud lo que hace que la dependencia de Río Gallegos a través de la RN 3, sea total.

Barrios localizados entre la RN 3 (a Chimen Aike) y la Av. Asturias: cuenta con servicios educativos, salud, recreación, transporte urbano, seguridad y cultural, además del comercio con importante variedad en los rubros que satisfacen las necesidades de la población de toda el área. Los lotes son de dimensión urbana, aunque el entramado es abierto. Es un área en proceso acelerado de consolidación, principalmente en los barrios San Benito, Bicentenario y Santa Cruz. Hacia la RN 3 y Chimen Aike se encuentra en un proceso incipiente de ocupación a través de la construcción de barrios por asociaciones gremiales y particulares. Este sector, está en pleno proceso de consolidación en esta última década, con servicios básicos de luz, agua, alumbrado público y gas, además de salud, educación, seguridad, comercial minorista y mayorista, depósitos y usos deportivos en ambientes cubiertos y al aire libre.

Por lo tanto, por las características que tienen ambos sectores, es que Cáceres en 2021 los identifica como Cuarta Franja Residencial Incipiente, donde cabe aclarar que, entre ambos, no hay comunicación.

Finalmente, el Área Central, la SFR, TFR y CFR, se presentan en la Figura 2: 


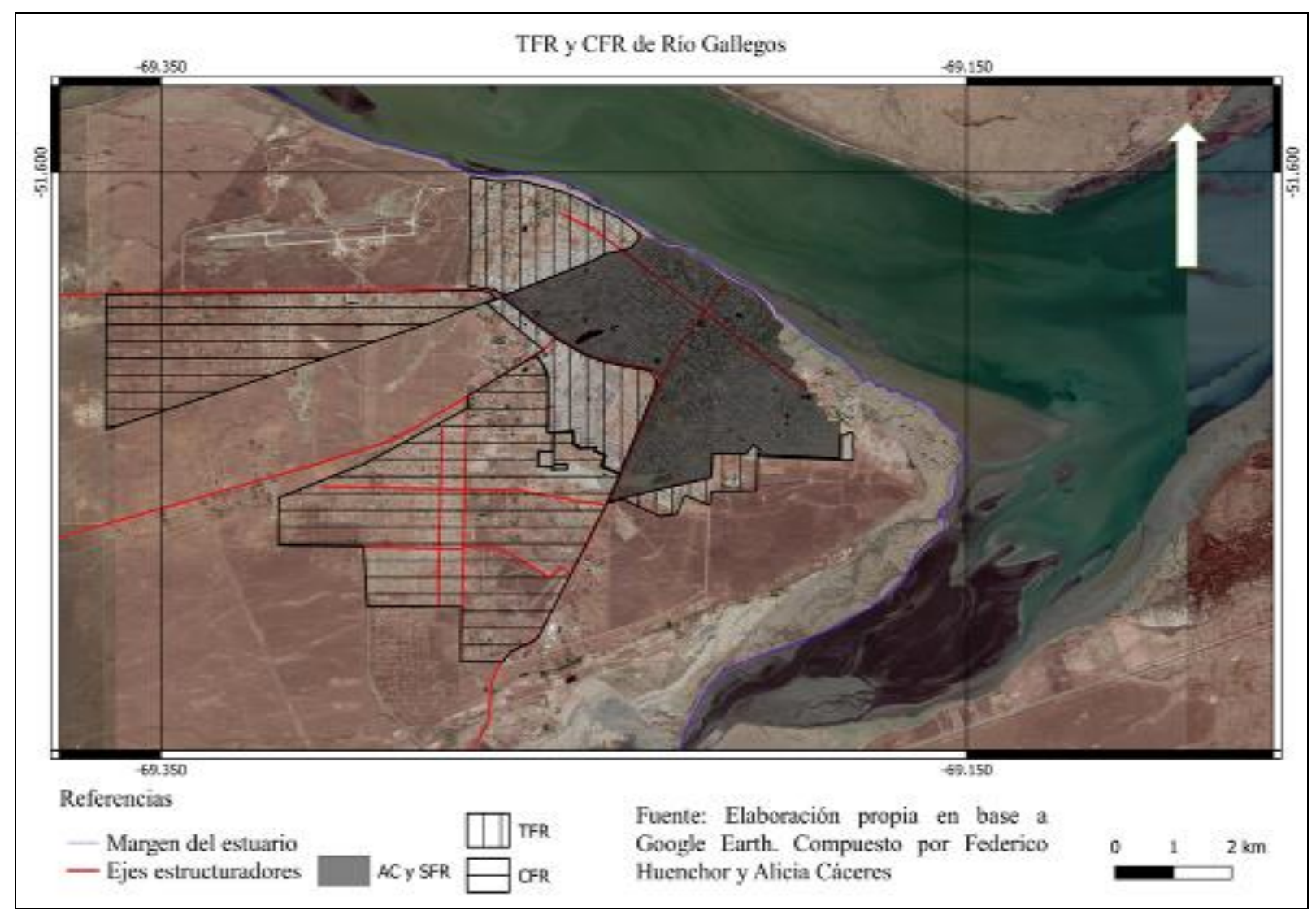

Figura 2: TFR y CFR de Río Gallegos. Elaboración propia en base a Google Earth. Compuesto por Federico Huenchor y Alicia Cáceres.

\section{Geografía cultural y Geografía de las religiones}

\section{Geografía cultural}

Tal como se realizó en el estudio correspondiente a la SFR de Río Gallegos, esta investigación se enmarca en la Geografía cultural renovada y en la Geografía de las religiones enmarcada en la primera.

Por ello, se procedió a la búsqueda, lectura comprensiva y selección de bibliografía referida a las Geografías antes mencionadas. A su vez, se consideró el marco teórico y conceptual desarrollado por Huenchor, Norambuena y Cáceres (2020) en "Culto Evangélico: Identificación, localización y caracterización en la Segunda Franja Residencial (SFR) de Río Gallegos”.

Desde fines del siglo XX, Paul Claval se destaca dentro de la Geografía cultural. Según este autor, la mencionada se desarrolla dentro de la Geografía humana y se enfoca en patrones e interacciones culturales (materiales e inmateriales), en relación con el ambiente y la organización humana del espacio (Claval, 2000).

Por otra parte, Shmite y Nin se han dedicado al estudio de la Geografía cultural y su renovación dentro de la Geografía. Estas autoras analizan las concepciones objeto de estudio de la Geografía y las articulan con las dimensiones culturales del nuevo orden mundial. Consideran que el espacio geográfico es reinterpretado y reconceptualizado en el contexto de la nueva Geografía cultural (Shmite y Nin: 2007). 
En términos generales, la Geografía ha transitado por distintas perspectivas teóricometodológicas, las cuales no son contradictorias sino complementarias. Claval, sostiene la existencia de tres perspectivas que han sostenido las investigaciones geográficas: la naturalista (espacio formado por los ecosistemas existentes en la superficie de la tierra); la funcionalista (de tres niveles: redes sociales, redes de comunicación y red de establecimientos humanos, de este modo, la estructura del espacio se encontraba dispuesta en capas sin que se pudieran diferenciar los distintos niveles entre sí) y; el enfoque cultural (corrige estas orientaciones al concebir el espacio como una escena donde los seres humanos se ofrecen al espectáculo, representan papeles que los valorizan, los enriquecen o les aseguran ciertos poderes, tiene en cuenta al individuo y las iniciativas de que es autor). Este último, da sentido a los decorados que los rodean y que, en gran medida, han construido, permite entrar en el universo de sus valores y creencias, y aclara las estrategias que retienen en su vida social, política o cultural. Estas tres perspectivas, no son contradictorias, sino complementarias. Hay que adoptarlas, una a una para medir todas las dimensiones de los hechos sociales en sus manifestaciones espaciales (Claval, 2002:38 citado por Shmite y Nin, 2007:171).

Shmite y Nin (2007), realizan un análisis de la Geografía cultural y su renovación hasta la actualidad. Realzan el carácter polisémico del concepto de cultura y citan autores que han desarrollado este marco teórico, por ejemplo, Hannerz (2002). Los territorios ya no pueden ser realmente contenedores de una única cultura, en la medida en que las personas se desplazan con sus significados y estos encuentran formas de desplazarse sin que las personas se muevan. Las primeras conjeturas de cambio hacia la nueva Geografía cultural se sitúan a mediados del siglo XX, posterior a la Segunda Guerra Mundial. Algunos investigadores identificados como "culturales", retoman y reinterpretan a H. Lefebre (Don Mitchell, Derek Gregory entre otros) con el objetivo, no de acentuar lo material o lo inmaterial, sino con el propósito de revisar las relaciones entre ambos. El texto de Henry Lefebvre (1974) es un referente fundamental por cuanto brinda un marco teórico que permite abordar la espacialización de las problemáticas desde la perspectiva cultural. Los espacios de representación, que el autor identifica, están colmados de elementos imaginarios y simbólicos que tienen su origen en la historia del lugar y en la historia de cada individuo que vive en ese lugar (Shmite y Nin, 2007).

La Geografía orientada hacia el campo de la cultura, ha desatado amplios debates durante las dos últimas décadas del siglo XX. En lugar de ser vista como objeto estático o monolítico, la cultura, considerada como evento, llevaría una definición interactiva y dinámica, poniendo énfasis analítico en las relaciones complejas de dominación, oposición y reapropiación que caracterizan a las subculturas minoritarias en sociedades urbanas contemporáneas. En los años noventa del siglo pasado, se profundizan y consolidan estudios que incorporan la perspectiva cultural que incluye el análisis simbólico del paisaje, entendido como una compleja construcción simbólica cultural. Peter Jackson (1999) sostiene que como resultado de los debates dentro de las Ciencias Sociales, se identifican una serie de nuevas direcciones dentro de la Geografía cultural, basados en enfoques ya existentes para la interpretación del paisaje, "[...] las nuevas direcciones de la Geografía cultural recurrieron a diversas tradiciones intelectuales, que iban desde la antropología y la teoría literaria hasta el feminismo y los estudios culturales contemporáneos, ensanchando así los límites de la Geografía cultural" (Jackson, 1999:43 citado por Shmite y Nin, 2007:176).

Sostiene Claval (1999) que la Geografía cultural es tan antigua como la Geografía humana. Ambas se desarrollaron desde la última década del siglo XIX, pero hoy se asiste a un renacimiento de la perspectiva cultural, el cual se vincula, no sólo a las transformaciones del 
mundo actual, sino también a la apertura hacia las interpretaciones de la subjetividad. Este renacimiento común al conjunto de las Ciencias Sociales, se produce a partir de la profunda reflexión en torno a la cuestión cultural que se desarrolla en las últimas décadas del siglo XX. A la luz de esta renovación, el autor especifica:

- Los hechos culturales son estudiados desde la óptica de la comunicación. La revolución de las comunicaciones ha trastornado la transmisión de los aspectos culturales tendiendo a uniformarse a nivel global, pero, en sentido inverso, hay otros factores que actúan acentuando las características de las culturas a escala local.

- La cultura es una realidad a escala local, generalmente de comunidades pequeñas más que de realidades globales. Para comprender los procesos culturales verdaderamente significativos, los geógrafos se basan en la experiencia de la gente, en sus contactos, en sus formas de hablar.

- Las categorías que los individuos aplican para analizar lo real son también creaciones culturales, representaciones resultado de su actividad individual y grupal. El orden social es culturalmente institucionalizado: todo agrupamiento social está constituido por un sistema de creencias y de ideologías que le dan sentido a los individuos y a la comunidad y, además, legitiman lo que está instituido.

- La cultura, es forjadora de identidades; da sentido a la existencia individual y grupal; incorpora valores y resulta indispensable para comprender las relaciones que dominan la vida de los grupos. Los individuos no dejan de instaurar nuevos valores, de construir nuevas clasificaciones y de trazar nuevas fronteras.

- Los individuos no son pasivos frente a la cultura, ésta es el vehículo que les ofrece posibilidades de apertura y crecimiento personal.

- El paisaje, es a la vez matriz e impronta de la cultura: matriz, porque las formas que lo estructuran contribuyen a transmitir usos y significados de una generación a otra; impronta, porque cada grupo social contribuye a modificar el espacio que utiliza al tiempo que graba las marcas de su actividad y los símbolos de su identidad.

La nueva Geografía cultural adquiere una dimensión antropológica, se identifica con las prácticas territoriales de los sujetos, con la cultura del lugar y está abierta a lo psicológico, al mundo de la percepción individual y colectiva. El individuo como agente, protagonista es el componente básico en el proceso de construcción del espacio. Es imprescindible analizar este rol como sujeto capaz de tomar decisiones y elegir, pero siempre en un contexto socializado. La importancia que adquieren las interpretaciones subjetivas y valorativas en los análisis geográficos, implican, no solo una innovación de las perspectivas de análisis (geografía cultural/humanística) sino que, paralelamente, se desarrolla un proceso de reelaboración de viejos conceptos e incorporación de nuevos. Los conceptos nuevos o renovados, funcionan como categorías analíticas de pensamiento para comprender y explicar las configuraciones espaciales del mundo actual. (Shmite y Nin, 2007:177-180)

Con relación a la Geografía cultural, desde el punto de vista anglosajón, se pueden tomar en consideración los artículos de varios referentes. Balasubramanian (2018), en Basics of cultural geography menciona que la Geografía y la Cultura están interrelacionadas. Esta última es la forma de vida que caracteriza a un grupo de personas y es un tema de estudio importante para 
los geógrafos. Entre los componentes de la Cultura se incluyen la religión, el lenguaje, la arquitectura, la cocina, la música, la danza, entre otros. Por las innumerables diferencias culturales que caracterizan a los pueblos y a las regiones del mundo, surge la necesidad de enfocarse en este subcampo disciplinar y es la Geografía cultural, el estudio de la relación que los humanos tienen con el lugar en el que se encuentran. Actualmente, esta última se enfoca en las migraciones, reconociendo que hay factores que dan lugar a estos movimientos, como la inseguridad, la falta de trabajo y de recursos, entre otros. La inestabilidad política o la guerra son también poderosos motivadores para la migración. Una economía pobre, desastres naturales continuos, o un fuerte deseo de vivir en una nación desarrollada son otros ejemplos de factores que empujan a las personas a migrar (Balasubramanian, 2018:2).

Por otra parte, el antes mencionado P. Claval en The Cultural approach in Geography: practices and narratives, menciona que el interés por los estudios que relacionan a la Cultura y la Geografía, yace en las perspectivas que proveen sobre la diferenciación cualitativa del espacio: para todos los grupos sociales, hay áreas las cuales manejan y otras que no pueden poner bajo control; hay espacios profanos y lugares donde lo sagrado se hace presente; existe una oposición entre las áreas que permiten a las familias o sociedades a sentirse en casa y los espacios públicos (Claval, 2006:16).

Dar lugar a las realidades culturales enriquece la geografía, el proceso transforma la disciplina. El enfoque cultural deja obsoletas concepciones de espacio que prevalecieron por mucho tiempo entre los geógrafos e introduce nuevas concepciones. El geógrafo debe considerar a la cultura como la totalidad de lo que se ha aprendido, es imposible desasociar el análisis de los hechos materiales del estudio de las representaciones. Asimismo, el enfoque cultural tiene una dimensión fundamentalmente temporal, muestra cómo las personas reciben una herencia del pasado, la enriquecen a través de sus experiencias en el presente y tratan de darle sentido a sus vidas a través de su proyección hacia el futuro. La construcción del yo y el desarrollo de la personalidad son importantes en esta perspectiva. El individuo siempre tiene que ser tomado en relación con su grupo (Ibídem:21).

En la Argentina y en la Geografía argentina, la Geografía cultural ha tenido, a lo largo del siglo XX, escaso desarrollo, renovándose hacia finales del mismo, en el país y el mundo. En la década de 1990, la Geografía social tuvo mayor preeminencia que la Geografía cultural. P. Claval, ha sido un gran aporte e influencia a la disciplina en el país, pero ha tenido escaso impacto en el desarrollo de investigaciones locales. La articulación entre migración, género y religión en la conformación de lugares es una línea que se ha comenzado a desarrollar desde finales de la década de 1990 y ha tomado relevancia a partir de los 2000 y hasta la actualidad, entre otras temáticas vinculadas con la Geografía cultural (Zusman et al, 2007).

\section{Geografía de las religiones}

Desde algunos referentes anglosajones, se puede destacar la importancia de los estudios vinculados a la Geografía de las religiones. Stoddard y Prorok (2003) en "Geografía de la religión y los sistemas de creencia", comienzan su escrito mencionando que, en la dimensión espacial y ambiental del comportamiento religioso, sus artefactos y actitudes son materia prima para los geógrafos, ya que las acciones y las convicciones motivadas espiritualmente juegan un papel importante en los asuntos humanos.

Las creencias y los comportamientos religiosos son importantes y están profundamente entrelazados con las formas de vida de numerosas comunidades alrededor del mundo; estas 
influencian a los entornos naturales, así como la localización y las características espaciales de fenómenos físicos específicos relacionados a la economía, la política, la cultura, entre otros. Aunque las actividades religiosas han mermado en ciertas regiones del mundo durante el último siglo, la religión continúa siendo un componente crítico de muchos eventos humanos. Es un elemento vital para entender, por ejemplo, los conflictos etno-religiosos sobre la posesión y el control de territorios específicos, las reuniones de millones de devotos que viajan a lugares particulares, los patrones de resultados electorales en varias democracias, y las disputas locales sobre el rol de las resoluciones gubernamentales de las instituciones públicas y el uso del suelo. Consecuentemente, mientras los geógrafos busquen explicar el comportamiento espacial de los humanos, habrá una necesidad de analizar la religión y los sistemas de creencias geográficamente (Stoddard y Prorok, 2003:263).

Por su parte, Warf y Winsberg (2008) presentan "La geografía de la diversidad religiosa en Estados Unidos". Allí los autores mencionan que la Geografía de la religión, ha recibido recientemente un interés creciente y renovado. Al abordar la espacialidad de la religión, los geógrafos han desenterrado la manera en que las creencias religiosas moldean la vida diaria, unificando a los individuos en comunidades más grandes basadas en la fe. En Estados Unidos, la religión ha sido una potente fuerza social, desde la fundación de la nación, esta ha jugado un papel importante en la política estadounidense (Phillips, 2006, citado por Warf y Winsberg, 2008:414), como queda ejemplificado históricamente por el movimiento antiesclavitud, socialismo agrario, la prohibición y la lucha por los derechos civiles, entre otros hechos significativos para la historia de la nación. En contraste con la mayoría de los países industrializados, este país exhibe mayores niveles de religiosidad (Hacket, 2003, citado por Warf y Winsberg,2008:414). La religión ha surgido como un potente asunto político, particularmente dada la influencia que tienen los activistas cristianos conservadores dentro del Partido Republicano (Wilcox, 1991 y Heineman, 1998, citados por Warf y Winsberg, 2008: 414). Las creencias religiosas tienen un papel central en las denominadas "guerras culturales" y en debates relacionados a asuntos como rezar en escuelas públicas, derechos reproductivos y contracepción, educación sexual, tolerancia a la homosexualidad, enseñanza de la evolución, investigación con células madre y otros temas importantes que se agrupan aproximadamente bajo la frase "valores morales" (Warf y Winsberg, 2008:413).

La Geografía de las religiones tradicionalmente ha tratado los temas de manera descriptiva, pero en los últimos años, en palabras de Santarelli y Campos, existe una nueva mirada de esta sub-rama como enfoque emergente vinculado a la renovada Geografía cultural, que aporta nuevos conceptos y categorías de análisis para comprender las diversas relaciones entre las sociedades y el espacio local vinculadas a prácticas basadas en el ejercicio de la fe, no solo en su tratamiento sino también en la enseñanza (Santarelli y Campos, 2011:2).

En el mundo de manera general y, en Latinoamérica hasta llegar a estudios locales, es posible encontrar estudios que ocupan la temática religiosa relacionada al territorio, ya sea describiendo, identificando, analizando y argumentando, entre otros procesos, en torno a las religiones. Es sabido que la religión que predomina en América Latina es el catolicismo, pero actualmente emergen otras prácticas en cuanto al ejercicio de la fe. En este sentido, algunos de los estudios que analizan el fenómeno de la religión en Brasil tienen en cuenta el impacto territorial que ha tenido la denominación Pentecostal perteneciente o considerada dentro del protestantismo o evangelismo. Fiani en 2011 presenta "Dinámicas del crecimiento pentecostal en la ciudad de Río de Janeiro. El caso de la Iglesia Universal del Reino de Dios”, el cual expone las principales características de esta religión cristiana en una de las principales ciudades de Brasil, describiendo los orígenes, características, los vínculos e influencia de la 
Iglesia en la política de ese país (Fiani, 2011).

En la Argentina, entre las formas de tratar la influencia de las religiones y la fe en el territorio, se pueden considerar estudios, sobre todo, a escala local. En estos se destacan las influencias de las religiones en el paisaje urbano, la presencia de las religiones en distintos sectores de la ciudad, los inventarios cartográficos, la veneración a imágenes relacionadas con la religión católica, entre otros temas.

Un aporte teórico conceptual relevante en relación al territorio, es el que realiza Flores en el año 2012: "Luján como hierópolis: del relato espacial al lugar religioso". En este artículo, la protagonista es la ciudad de Luján (provincia de Buenos Aires), principal centro religioso de Argentina. Anualmente, la localidad recibe millones de visitantes que arriban motivados por el centro hierofánico que constituye la Basílica Nacional de Nuestra Señora de Luján. Situado desde una perspectiva cultural de análisis del territorio, este trabajo explora el proceso de producción del espacio religioso que condujo a la invención de la ciudad como hierópolis, también avanzó en la indagación de las representaciones espaciales y espacios de representación que operaron a lo largo de los siglos y cuyo resultado final es la configuración del escenario religioso actual. Finalmente, se analizan los geosímbolos irrumpidos como íconos de la memoria territorial que todo el tiempo remiten a una versión hegemónica del relato espacial (Flores, 2012:137).

Por otra parte, quienes también analizan la influencia en el territorio de la religión y en los medios de comunicación, son Carbonelli y Mosqueira, ellos presentan el artículo "Luis Palau en Argentina: Construcción mediática del cuerpo evangélico, disputa por el espacio público y nuevas formas de territorialidad". En él analizan el impacto de un megaevento realizado por un evangelista de fama mundial en la ciudad de Buenos Aires en 2008, el "Festival con Luis Palau", la estructura organizativa que lo propició y los dispositivos de construcción del acontecimiento por parte de los medios de comunicación (Carbonelli y Mosqueira,2008:65). Este evento evangélico permitió, el despliegue "heráldico" de las "patrias cristianas", en el centro simbólico y geográfico más sensible de la identidad nacional argentina: el obelisco de Buenos Aires. El acto cristiano, tuvo una función doble: por un lado, afirmó la cohesión interna y al mismo tiempo, "espectacularizó" su unidad hacia el exterior como "pueblo diferenciado". El debate mediático en torno al "Festival con Luis Palau" y el festival en sí mismo revelan la superposición de dos lógicas territoriales disímiles que entran en conflicto. Por un lado, una lógica móvil del lado de los pueblos-patria evangélicos y por otro, una lógica anclada al espacio "nacional" por parte de los medios de comunicación de masas. Se desarrolla una disputa discursiva por nominar el dominio del espacio, o lo que es lo mismo, establecer qué tipo de configuración se le dará a éste: una lógica que mantiene una referencia a la Nación y por lo tanto, no admite nuevos símbolos religiosos o una lógica transnacional, que en el mismo movimiento de diluir viejas fronteras, instaura otras (Carbonelli y Mosqueira, 2008:86-87). Este estudio expone las tensiones en cuanto al poder sobre un espacio significativo a escala nacional, ocupado en momentos particulares de la historia del país, sobre todo en relación a la dimensión política, el obelisco de la ciudad de Buenos Aires. El hecho de que un evento religioso no católico deje al descubierto la apropiación temporal de un espacio relacionado con lo político y lo nacional genera controversia. Sucede lo mismo en ciudades del interior del país en donde en los últimos años las iglesias evangélicas han comenzado a hacerse visibles en lugares destacados en los centros urbanos.

Estos dos estudios son solo algunos de los que se encuentran con relación a la Geografía de las religiones en la Argentina y, sin duda, una de las obras que más se destaca en este marco 
teórico es el presentado por Carballo y Flores en 2019, "Geografías de lo sagrado en la contemporaneidad". En su primera parte, este trabajo presenta el espacio, la cultura y la religión, miradas desde Brasil y recoge el dinamismo y la influencia de este último concepto vinculado al territorio. En una segunda parte, expone otros procesos asociados como las procesiones, los viajes religiosos y las peregrinaciones tanto en Brasil como en Argentina. En la tercera parte, se presentan los escenarios festivos, rituales y religiosidad en el espacio, en este apartado se consideran trabajos de Argentina, México y Brasil. En la cuarta parte, los autores compilan trabajos que consideran las movilidades, espacios y religiosidad principalmente en la Argentina. En la quinta parte, se destaca la espacialidad de lo religioso, se tienen en cuenta estudios sobre la influencia en el espacio de santos populares como el Gauchito Gil en Argentina, la apropiación del espacio con prácticas artísticas en ciudades como Comodoro Rivadavia, elementos de la naturaleza en las prácticas sagradas mapuches, entre otros estudios con base en Brasil y Argentina (Carballo y Flores, 2019).

\section{El culto evangélico en la provincia de Santa Cruz}

Con relación al culto evangélico en Santa Cruz y particularmente en Río Gallegos, tal como se realizó en la investigación "Culto Evangélico: Identificación, localización y caracterización en la Segunda Franja Residencial (SFR) de Río Gallegos", de Huenchor, Norambuena y Cáceres (2020), la obra que se consideró fue la presentada por Mancilla (2009), que recorre históricamente la conformación del mismo en la provincia. Este autor, es hasta el momento, quien hace una suerte de historia del evangelismo en Santa Cruz y Río Gallegos.

Los primeros protestantes en Santa Cruz fueron anglicanos y tuvieron gran visibilidad social en las primeras etapas de la ocupación del territorio, la que disminuyó entre las décadas de 1920 y 1940, por lo que no se estableció una iglesia permanente. Las necesidades religiosas (casamientos, bautizos, funerales, etc.) de Río Gallegos y Puerto San Julián eran cubiertas por la misión de Saint James de Punta Arenas (Chile) o por servicios religiosos itinerantes.

La conversión al catolicismo de la comunidad, fue uno de los causantes de esta baja demanda de bienes y servicios religiosos evangélicos. En 1943, comienza a aplicarse una política de control y seguimiento a causa de una creciente preocupación por la expansión de "propaganda protestante" en el país. En 1945 en Santa Cruz circuló una nota dirigida al gobernador del Territorio, las comisarías y subcomisarías, en la que se advertía sobre "el peligro de la propaganda religiosa, especialmente la metodista". En el año 1950, las restricciones que afectaban a los protestantes, como la prohibición de emitir programas radiales, negarles permisos para organizar encuentros, entre otros, fueron disminuyendo por el enfrentamiento de Perón con la Iglesia Católica; esto posibilitó la apertura hacia el reconocimiento de las minorías religiosas en comparación con la década anterior. Este contexto dio comienzo al "núcleo formativo del campo evangélico", a partir de tres modos y etapas de evangelización: por el aporte migratorio, por la interacción de los grupos evangélicos locales y por acciones esporádicas de misiones evangelizadoras externas.

En las décadas de 1950 y 1960, se forman grupos evangélicos más estables a nivel local, la movilidad y el crecimiento en cantidad de miembros se intensificó con la inmigración venida del sur de Chile principalmente, la cual no se desprendía de su identidad evangélica heterogénea (sobre todo, pentecostales, bautistas y en menor medida, metodistas).

Desde fines de los años de la década de 1960, la Municipalidad comenzó a regular las actividades externas de evangelización realizadas por grupos no católicos. Comienzan a llegar 
a Río Gallegos, pastores que inician iglesias permanentes en la ciudad, templos con denominaciones que perduran hasta la actualidad.

Mancilla (2009), menciona dos eventos que marcan un antes y después del culto evangélico en la provincia y la ciudad en la segunda mitad del siglo XX. Estos son: la celebración de la $1^{\mathrm{a}}$ Convención constitutiva del Movimiento Cristiano y Misionero de la Patagonia, que contó con representantes de Santa Cruz (Río Gallegos, Río Turbio, San Julián y Puerto Deseado), Chubut (Comodoro Rivadavia), Tierra del Fuego (Río Grande y Ushuaia) y de la República de Chile (Puerto Natales) y; el inicio de la Iglesia Evangélica Bautista de Río Gallegos, que integra el grupo de primeras iglesias en la ciudad.

Finalmente, en este proceso de formación convergen grupos protestantes diversos que se constituyeron como una comunidad evangélica inicial con una identidad religiosa caracterizada por la necesidad de socialización religiosa y cohesión social, a nivel local. El primer protestantismo fue representado por los anglicanos, el segundo por metodistas y adventistas y el tercero, por movimientos pentecostales.

\section{Denominaciones relacionadas al culto evangélico en Río Gallegos}

Se caracterizó a las Iglesias Cristianas Evangélicas presentes en Río Gallegos con o sin denominación/es según lo expuesto por varios autores, sitios web, webs oficiales, blogs, wikis, diccionarios, entre otros espacios dedicados a la religión objeto de estudio (Norambuena, 2019). En "Culto Evangélico: Identificación, localización y caracterización en la Segunda Franja Residencial (SFR) de Río Gallegos”, de Huenchor, Norambuena y Cáceres (2020), se encuentra tal caracterización tenida en cuenta para la actual investigación. Se han considerado las denominaciones allí presentadas para ser identificadas y localizadas en la TFR y CFR. Estas son por orden alfabético: Adventista, Apostólica, Bautista, Metodista o Metodismo, Misionera, Pentecostal o Pentecostalismo, Unión de las Asambleas de Dios/ Asambleas de Dios. En segundo lugar, las Iglesias Cristianas Evangélicas sin denominación (Huenchor et al,2020:134).

Tal como en el estudio referido a la SFR de Río Gallegos relacionado al culto evangélico, para este estudio se utilizaron los conceptos clave de: Culto, Iglesia Evangélica, Evangélicos, Fichero de culto, Iglesia, Persona Jurídica, Templo y Uso del suelo (Huenchor et al, 2020: 138).

\section{RESULTADOS, ANÁLISIS Y DISCUSIÓN}

\section{Metodología}

La metodología del trabajo es descriptiva con respecto a la identificación y la caracterización de templos evangélicos en la TFR y CFR de la ciudad de Río Gallegos y, es exploratoria por la localización que se considera en el presente trabajo; estos sectores no se habían estudiado anteriormente con relación a la temática.

En primer lugar, se buscó, leyó comprensivamente, seleccionó y actualizó la bibliografía de la Geografía cultural y de la Geografía de las religiones, en general y en particular las pertenecientes al culto evangélico, con el fin de ampliar el marco teórico- conceptual. 
En segundo lugar, sobre la estructura interna del ejido municipal de Río Gallegos, para las dos áreas estudiadas en este trabajo, Cáceres (2021) actualiza el límite sur-oriental de la TFR y por primera vez, el área rururbana intraejidal la denomina Cuarta Franja Residencial (CFR).

En tercer lugar, se diseñó una base de datos en planilla de cálculo en Excel, con el fin de relevar los templos evangélicos en el área de estudio. Se programó una salida de campo para realizar observación directa, pero la misma debió ser cancelada debido al contexto de pandemia causado por el virus SARS-CoV-2, por esta razón, se realizó un ajuste metodológico y dicha salida fue reemplazada por la búsqueda de templos de manera indirecta a través del programa informático cartográfico Google Earth y por recorridos informales en el área de estudio, en las cuales se capturaron imágenes para un registro fotográfico de las manifestaciones del culto evangélico.

En cuarto lugar, se adoptó la caracterización realizada por Norambuena (2019, publicada en 2020:134) sobre las denominaciones de las iglesias evangélicas presentes en Río Gallegos, para luego identificar aquellas que se encuentran en la TFR y CFR de Río Gallegos y posteriormente, localizar, describir e interpretar la territorialidad de los elementos pertenecientes al culto evangélico (templos, radios y escuelas, entre otros).

En quinto lugar, se confeccionó cartografía temática a través del SIG Qgis Hannover de los templos evangélicos en la TFR y CFR de Río Gallegos, los cuales se representaron a través de las implantaciones puntuales e interpretados por el nivel de medición nominal propiamente dicho, de este modo, se representó con la variable visual forma y color. Cabe mencionar que para toda la investigación realizada en el marco del Proyecto de Investigación 29/A427-1, se adoptaron criterios únicos de tipos de implantación, niveles de medición y variables visuales según el tipo de denominación, con el fin de obtener cartografía homologada.

Por último, se redactaron dos informes, uno bajo las normas editoriales de Informe Científico Técnico UNPA (ICT), y otro de divulgación para ser elevado a las autoridades municipales y provinciales como aporte a la planificación urbana y territorial, como así también el informe del desempeño del becario y el trabajo realizado. ${ }^{1}$

\section{El culto evangélico en la Tercera y Cuarta Franja Residencial de Río Gallegos}

A continuación, con relación a la caracterización de las denominaciones evangélicas en la TFR y CFR, se presentan todas las edificaciones relacionadas a este culto, producto del relevamiento realizado y representadas en la Figura 3. Se registraron un total de trece templos, ocho con sus coordenadas geográficas y cinco con su localización aproximada. Cabe aclarar que, ninguno de los templos identificados presenta anexos, radios, escuelas, comedores $\mathrm{u}$ otros fuera del templo.

La TFR presenta tres sectores: Este, Sur y Oeste, este último, único sector en presentar templos pertenecientes al culto evangélico, con la iglesia "Comunión de todos los Santos", de denominación pentecostal en la calle Samuel Morse y la iglesia "Hay vida en Jesús", en la

\footnotetext{
${ }^{1}$ Cabe mencionar que el desarrollo de la beca, coincidió con la pandemia antes mencionada, por tanto, los encuentros entre la directora, la co-directora y el becario fueron virtuales. Para tal efecto se utilizó de forma gratuita el servicio de videotelefonía de Meet desde las direcciones de correo electrónico institucionales, además, se trabajó de manera colaborativa en el servicio de alojamiento de archivos Drive, ambas herramientas de ofimática se encuentran en el paquete de servicios Suite provistos por la empresa Google, ya que la UNPA posee licencias educativas que le permite acceder a los docentes y estudiantes de forma gratuita.
} 
categoría "Sin Denominación". Con respecto al uso del suelo anterior, en la TFR se visualizó un templo con uso anterior residencial, mientras que, en el otro, no se pudo observar; ambos son templos principales (Tabla 1).

\begin{tabular}{|c|c|c|c|c|c|}
\hline Nombre & Denominación & $\begin{array}{c}\text { Localización L.S., } \\
\text { L.O. }\end{array}$ & Sector & $\begin{array}{c}\text { Uso del suelo } \\
\text { anterior }\end{array}$ & $\begin{array}{c}\text { Anexo o } \\
\text { principal }\end{array}$ \\
\hline $\begin{array}{c}\text { Iglesia Hay } \\
\text { vida en Jesús }\end{array}$ & SD & $\begin{array}{c}36^{\prime} 34.01^{\circ} \mathrm{S} ; \\
69^{\circ} \\
14^{\prime} 35.22^{\prime \prime} \mathrm{O}\end{array}$ & Oeste & No observado & Principal \\
\hline $\begin{array}{c}\text { Comunión de } \\
\text { los Santos }\end{array}$ & Pentecostal & $\begin{array}{c}36^{\prime} 57.61^{\circ} \mathrm{S} ; \\
69^{\circ}\end{array}$ & Oeste & Residencial & Principal \\
& & $15^{\prime} 12.21^{\prime \prime} \mathrm{O}$ & & & \\
\hline
\end{tabular}

Tabla $\mathrm{N}^{\circ}$ 1. Culto evangélico en la TFR de Río Gallegos. Fuente: relevamiento de templos a través de Google Earth. Elaboración propia. SD: sin denominación.

La variable "uso del suelo anterior", no se pudo observar para la Iglesia Hay vida en Jesús, ya que a la hora de realizar observación indirecta en Google Earth el mismo no proporcionó imagen sobre la edificación.

En la CFR, nueve templos presentan como uso del suelo anterior, el religioso y dos el residencial; siete templos son principales y cuatro son anexos. Tabla $\mathrm{N}^{\circ} 2$.

La CFR tiene un desarrollo norte-sur y se presentan 2 sectores: el sector Ruta 3-terraplen y el sector Asturias-Chimen Aike.

De estos, el único sector en presentar templos evangélicos es el Sector Asturias-Chimen Aike, con la totalidad de templos presentes en toda la franja, de estos, seis no presentan una denominación concreta, cuatro son Asambleas de Dios y uno es de denominación Pentecostal.

\begin{tabular}{|c|c|c|c|c|c|}
\hline Nombre & Denominación & $\begin{array}{l}\text { Localización L.S, } \\
\text { L. O/ Loc. } \\
\text { aproximada }\end{array}$ & Sector & $\begin{array}{c}\text { Uso del suelo } \\
\text { anterior }\end{array}$ & $\begin{array}{r}\text { Anexo o } \\
\text { principal }\end{array}$ \\
\hline $\begin{array}{c}\text { Iglesia } \\
\text { Pentecostal } \\
\text { Unida de la } \\
\text { Argentina } \\
\text { "Tiempos de } \\
\text { Conquista" }\end{array}$ & Pentecostal & $\begin{array}{c}\text { Calle } 3 \text {, entre } \\
\text { Calle } 4 \text { y } 6\end{array}$ & $\begin{array}{l}\text { Asturias- } \\
\text { Chimen } \\
\text { Aike }\end{array}$ & Religioso & Principal \\
\hline $\begin{array}{c}\text { Iglesia } \\
\text { Asamblea de } \\
\text { Dios }\end{array}$ & $\begin{array}{c}\text { Asamblea de } \\
\text { Dios }\end{array}$ & $\begin{array}{l}51^{\circ} 39^{\prime} 28.32 " \mathrm{~S} \\
69^{\circ} 39^{\prime} 28.00^{\prime \prime} \mathrm{O}\end{array}$ & $\begin{array}{l}\text { Asturias- } \\
\text { Chimen } \\
\text { Aike }\end{array}$ & Religioso & Anexo \\
\hline
\end{tabular}




\begin{tabular}{|c|c|c|c|c|c|}
\hline $\begin{array}{c}\text { Iglesia } \\
\text { Asamblea de } \\
\text { Dios en } \\
\text { Misiones }\end{array}$ & $\begin{array}{l}\text { Asamblea de } \\
\text { Dios }\end{array}$ & $\begin{array}{l}51^{\circ} 38^{\prime} 59.22^{\prime \prime S} \\
69^{\circ} 18^{\prime} 47.48^{\prime \prime} \mathrm{O}\end{array}$ & $\begin{array}{l}\text { Asturias- } \\
\text { Chimen } \\
\text { Aike }\end{array}$ & Religioso & Anexo \\
\hline $\begin{array}{c}\text { Iglesia } \\
\text { Cristiana } \\
\text { Auditorio Bet } \\
\text { El }\end{array}$ & $\begin{array}{l}\text { Asamblea de } \\
\text { Dios }\end{array}$ & $\begin{array}{l}51^{\circ} 39^{\prime} 48.86 " \mathrm{~S} \\
69^{\circ} 16^{\prime} 27.71^{\prime \prime} \mathrm{O}\end{array}$ & $\begin{array}{l}\text { Asturias- } \\
\text { Chimen } \\
\text { Aike }\end{array}$ & Religioso & Anexo \\
\hline $\begin{array}{l}\text { Iglesia Cristo } \\
\text { toma tu lugar }\end{array}$ & $\begin{array}{l}\text { Asamblea de } \\
\text { Dios }\end{array}$ & $\begin{array}{l}51^{\circ} 39^{\prime} 10.27^{\prime \prime S} \\
69^{\circ} 16^{\prime} 48.59^{\prime \prime O}\end{array}$ & $\begin{array}{l}\text { Asturias- } \\
\text { Chimen } \\
\text { Aike }\end{array}$ & Religioso & Anexo \\
\hline Impa Kairos & SD & $\begin{array}{l}51^{\circ} 38^{\prime} 58.22 " \mathrm{~S} \\
69^{\circ} 17^{\prime} 04.35^{\prime \prime} \mathrm{O}\end{array}$ & $\begin{array}{l}\text { Asturias- } \\
\text { Chimen } \\
\text { Aike }\end{array}$ & Religioso & Principal \\
\hline $\begin{array}{c}\text { Iglesia } \\
\text { Evangélica } \\
\text { CCR (Centro } \\
\text { Cristiano } \\
\text { Refugio) }\end{array}$ & SD & $\begin{array}{c}\text { Calle } 13 \text {, entre } \\
26 \text { y } 28\end{array}$ & $\begin{array}{l}\text { Asturias- } \\
\text { Chimen } \\
\text { Aike }\end{array}$ & Residencial & Principal \\
\hline $\begin{array}{c}\text { Iglesia } \\
\text { Evangélica } \\
\text { "Cristo el Rey" }\end{array}$ & SD & $\begin{array}{c}\text { Calle } 5 \text {, entre } 26 \\
\text { y } 28\end{array}$ & $\begin{array}{l}\text { Asturias- } \\
\text { Chimen } \\
\text { Aike }\end{array}$ & Religioso & Principal \\
\hline $\begin{array}{c}\text { Ministerio } \\
\text { Evangélico } \\
\text { Pueblo de Dios }\end{array}$ & SD & $\begin{array}{l}51^{\circ} 39^{\prime} 09.07^{\prime \prime S} \\
69^{\circ} 17^{\prime} 39.47^{\prime \prime} \mathrm{O}\end{array}$ & $\begin{array}{l}\text { Asturias- } \\
\text { Chimen } \\
\text { Aike }\end{array}$ & Religioso & Principal \\
\hline $\begin{array}{c}\text { Cumbre } \\
\text { Mundial de los } \\
\text { Milagros }\end{array}$ & SD & $\begin{array}{c}\text { Calle } 5 \text {, entre } 10 \\
\text { y } 12\end{array}$ & $\begin{array}{l}\text { Asturias- } \\
\text { Chimen } \\
\text { Aike }\end{array}$ & Religioso & Principal \\
\hline $\begin{array}{c}\text { Iglesia } \\
\text { Evangélica } \\
\text { Cristo el } \\
\text { Camino }\end{array}$ & SD & $\begin{array}{c}\text { Calle } 34 \text {, entre } \\
13 \text { y } 17\end{array}$ & $\begin{array}{l}\text { Asturias- } \\
\text { Chimen } \\
\text { Aike }\end{array}$ & Residencial & Principal \\
\hline
\end{tabular}

Tabla $\mathrm{N}^{\circ}$ 2. Culto Evangélico de la CFR en Río Gallegos. Fuente: relevamiento de templos a través de Google Earth y recorridos informales. Elaboración propia. SD: sin denominación. 


\section{Discusión: Predominio del culto evangélico en la CFR}

En las áreas de estudio, de las denominaciones evangélicas presentes en Río Gallegos, no se identificaron templos adventistas, apostólicos, bautistas o misioneros.

Del total de templos, la TFR solamente posee dos, mientras que los once restantes se ubican en la CFR, de este modo es la franja que más posee. De las ocho denominaciones evangélicas presentes en toda la ciudad, solamente se encontraron tres claramente indicadas en el área de estudio y ninguna comparte denominación con otras.

La legislación vigente sobre zonificación en Río Gallegos contempla el uso del suelo religioso, dentro de la categoría conocida con el nombre de "servicio a la comunidad", relacionándose así con los templos pertenecientes al culto evangélico en la TFR y CFR. Sin embargo, el municipio no tiene disponible una base de datos sobre el culto evangélico en Río Gallegos en general y, en particular, para las áreas de estudio. En cuanto a las denominaciones identificadas, localizadas y caracterizadas por área (Tabla 3), se obtuvo el siguiente detalle:

\begin{tabular}{|c|c|c|}
\hline Denominación & Templos TFR & Templos en la CFR \\
\hline Pentecostal & 1 & 1 \\
\hline Asambleas de Dios & 0 & 7 \\
\hline Sin denominación & 1 & 3 \\
\hline
\end{tabular}

Tabla No3: Templos en la TFR y CFR de las denominaciones identificadas, localizadas y caracterizadas. Fuente: Elaboración propia.

La identificación, localización y caracterización de los templos del culto evangélico según los sectores dentro de la TFR y la CFR, se representa en la Figura 3: 


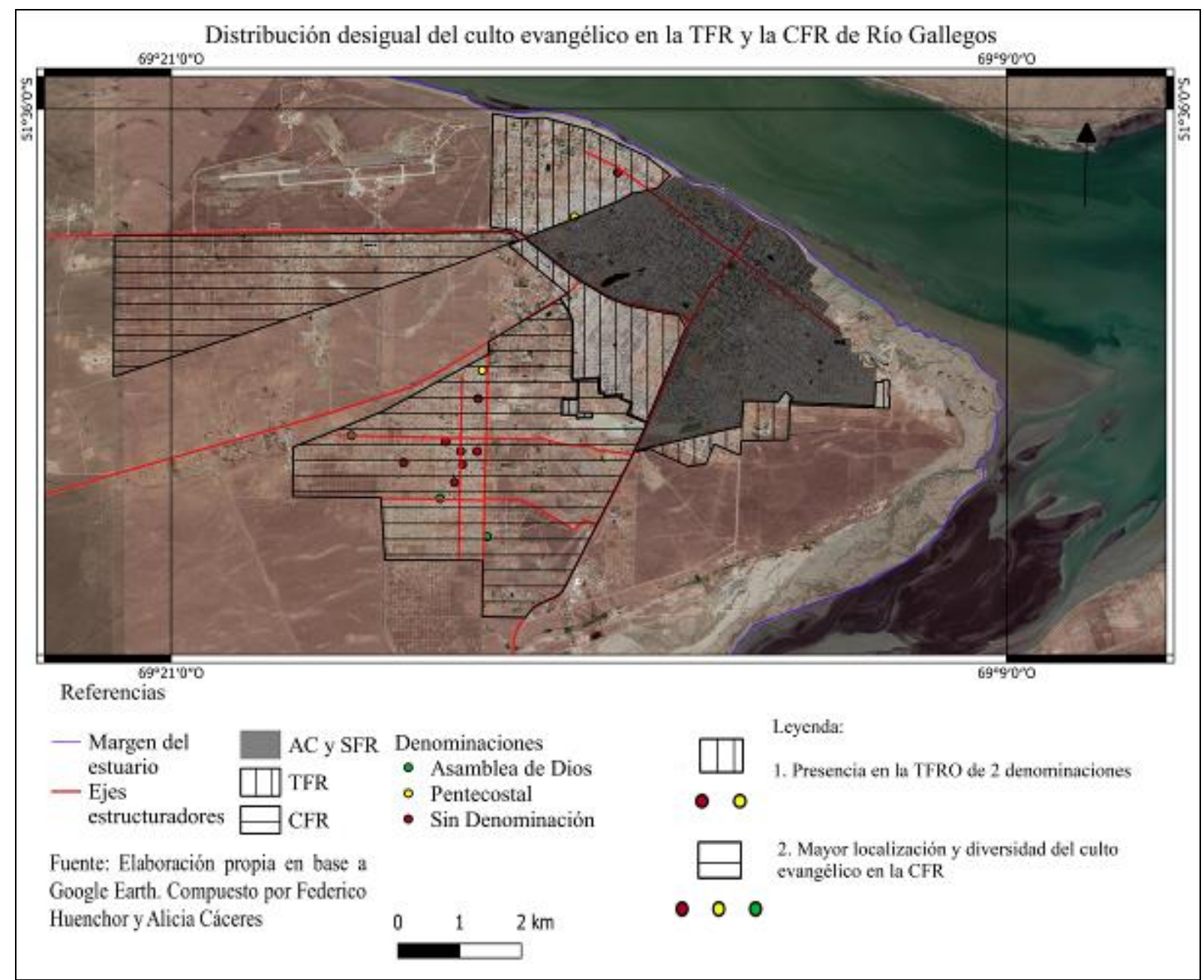

Figura 3: Distribución desigual del culto evangélico en la TFR y CFR de Río Gallegos. Elaboración propia en base a Google Earth. Compuesto por Federico Huenchor y Alicia

\section{Cáceres.}

En síntesis, según la Tabla 3 y la Figura 3, el $75 \%$ de los edificios destinados al culto evangélico se localizan en la CFR, se desprende la hipótesis de que el valor elevado de la tierra en la TFR con respecto a la CFR, no facilita la compra de un lote para la construcción de templos. El alto valor de las tierras en la TFR se debe a que es un área con servicios, además de los básicos, alumbrado público y pavimento de manera parcialmente, también por la red de vinculación continua con el resto de la Segunda Franja Residencial y con el Área Central, situación contraria a la CFR, en donde el valor de la tierra es inferior, la red de vinculación es discontinua y sin alumbrado público.

A continuación, se presenta parte del registro fotográfico que fue tomado durante los recorridos informales: 


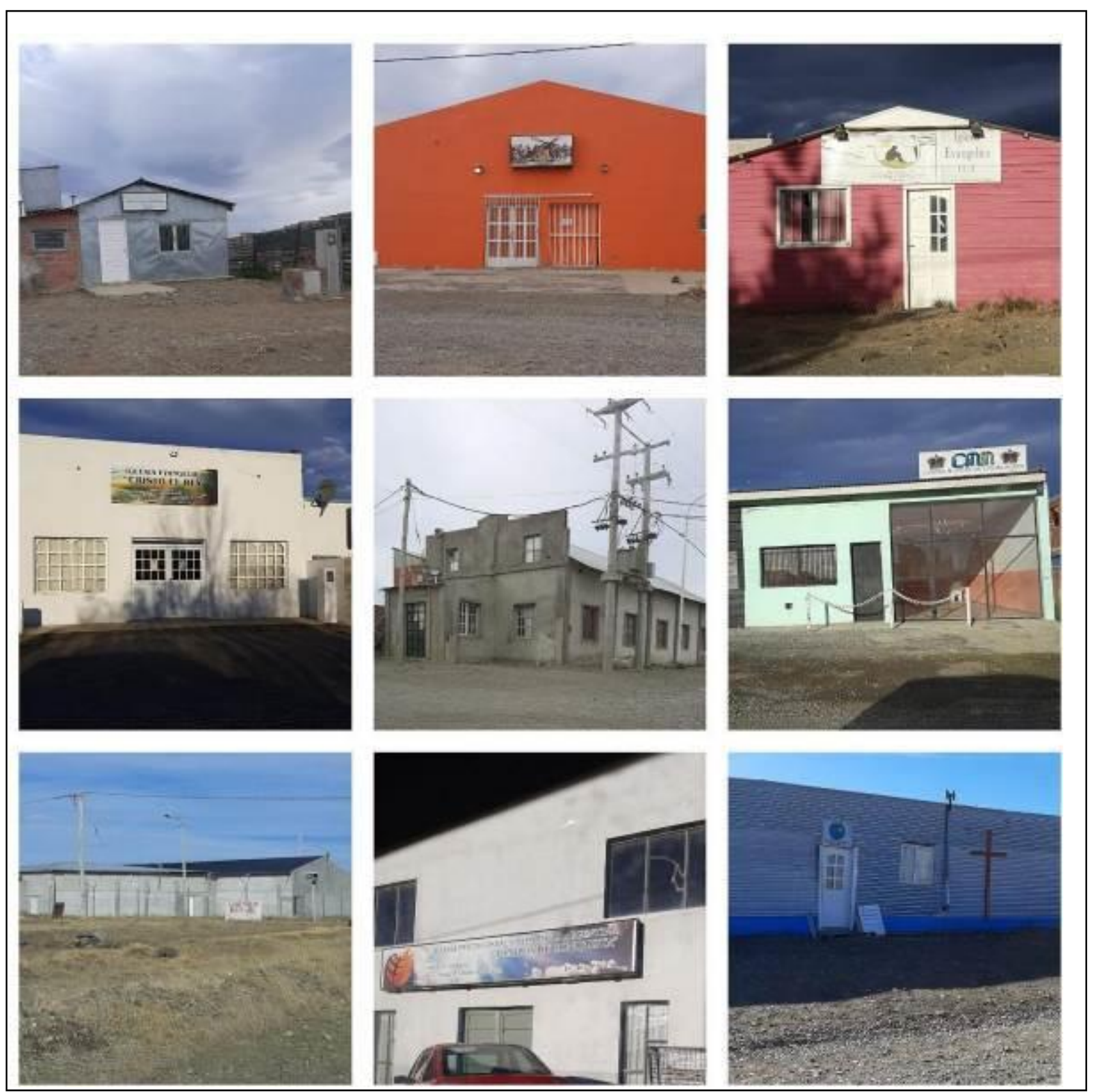

Figura 4: Registro fotográfico tomado en salidas informales. Fila $\mathrm{N}^{\circ} 1$ de izquierda a derecha: Iglesia Evangélica Cristo El Camino, Iglesia Cristiana Hijos del Altísimo Cristo toma tu lugar, Iglesia Evangélica C.C.R.- Fila $\mathrm{N}^{\circ} 2$ de izquierda a derecha: Iglesia Evangélica Cristo el Rey, Iglesia Asamblea de Dios, Iglesia Evangélica Cumbre de los Milagros- Fila N³ de izquierda a derecha: Iglesia Cristiana Auditorio Bet El, Iglesia Pentecostal Unida de la Argentina Tiempos de Conquista, Ministerio Evangélico Pueblo de Dios. Fuente: Mónica Norambuena

Finalmente, se han considerado los principales aportes teóricos de la Geografía cultural y de la Geografía de las religiones para este estudio. Con relación a la primera, la religión es uno de los componentes principales de la cultura y está forja identidades; da sentido a la existencia tanto del individuo como al grupo. También es la cultura una influencia en la modificación de los paisajes, ya que cada grupo social contribuye a modificar el espacio que utiliza al tiempo que graba las marcas de su actividad y los símbolos de su identidad. De la Geografía de las religiones, se considera que las acciones y las convicciones motivadas espiritualmente juegan un papel importante en los asuntos humanos, las creencias y los comportamientos religiosos 
están profundamente integrados a las formas de vida de numerosas comunidades alrededor del mundo, e influencian los entornos naturales, la localización y las características espaciales de fenómenos físicos específicos, relacionados a la economía, la política, la cultura, entre otros.

\section{CONCLUSIÓN}

Con relación a los objetivos planteados, el primero relevar y analizar bibliografía específica sobre la Geografía cultural y la Geografía de las religiones en particular y, el segundo identificar, localizar, caracterizar y cartografiar manifestaciones culturales religiosas relacionadas al culto evangélico en la TFR y CFR de Río Gallegos, se han cumplido.

Según la hipótesis planteada, las manifestaciones culturales religiosas relacionadas al culto evangélico, se pudo cumplir con la identificación, localización y caracterización en TFR y CFR de Río Gallegos, en el marco de la Geografía de las religiones.

Este trabajo, desde el punto de vista académico, resulta un gran aporte al estudio de la Geografía de las religiones, concretamente del culto evangélico, en Río Gallegos, en la provincia de Santa Cruz y en la región patagónica. Asimismo, es un gran aporte para la Municipalidad de Río Gallegos, para el conocimiento sistematizado del culto evangélico en la TFR y CFR.

\section{RECOMENDACIONES}

Se recomienda a la Municipalidad de Río Gallegos, el uso de la base de datos que aporta esta investigación y su actualización permanente. Asimismo, se sugiere a este organismo actualizar la nómina y los límites concretos de los barrios que componen a la ciudad, con cartografía georreferenciada.

\section{AGRADECIMIENTOS}

Se agradece al personal de la Comisaría $\mathrm{N}^{\circ}$, por la información provista para delimitar los barrios presentes en la CFR.

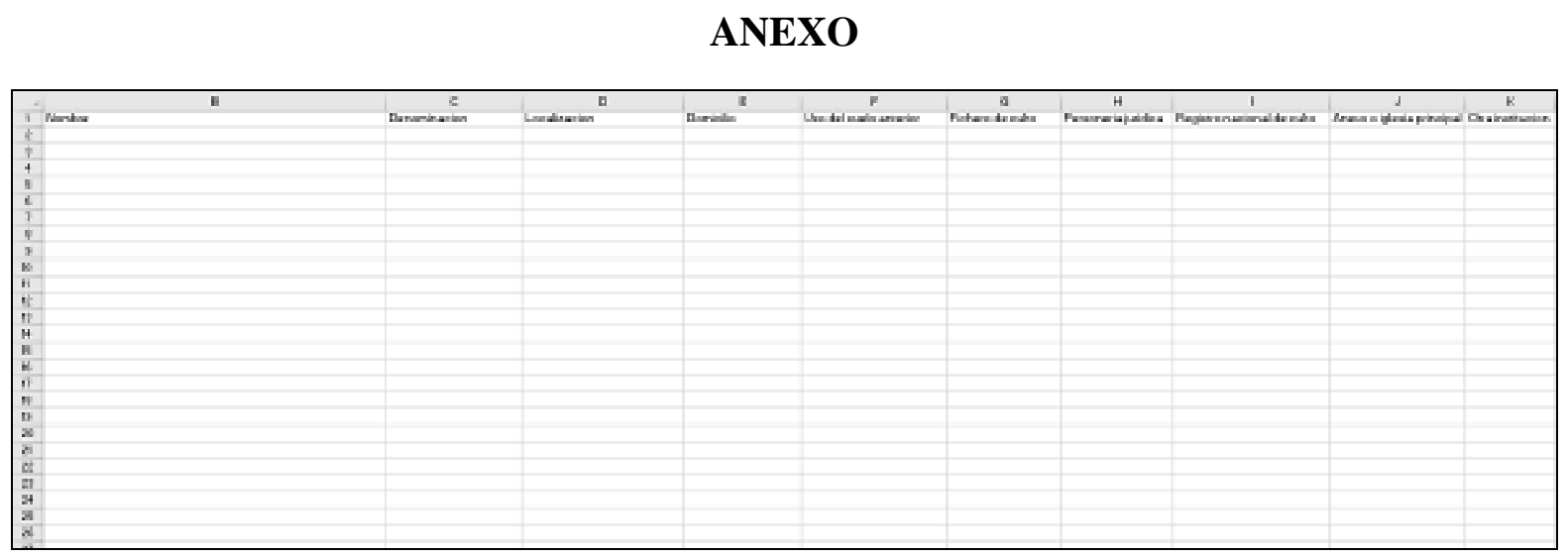

Planilla de relevamiento 


\section{REFERENCIAS}

AMPUERO, C. (2011). La veneración del Nazareno de Caguach en la ciudad de Río Gallegos, Patagonia Austral Argentina. Trabajo final del seminario Filosofía y Teología del Doctorado en Geografía, Universidad del Salvador. Buenos Aires. Inédito.

BALASUBRAMANIAN, A. (2018). Basics of Cultural Geography. Reporte técnico. Páginas 2-10. Descargado el día 27 de marzo de 2021. Disponible en: https://www.researchgate.net/publication/325781826_Basics_of_Cultural_Geography

CÁCERES, A.; MARENCO, S.; SOTO, J.; OJEDA, S.; BUSTOS, R. (1999). Conflictos en la gestión del crecimiento urbano en sistemas municipales ejidales. Río Gallegos. Revista Universitaria de Geografía. Volumen $8 \mathrm{~N}^{\circ} 1$ y 2.

CÁCERES, A. P. (2000). Geografía Urbana: estructura y paisajes urbanos de Santa Cruz. El Gran Libro de Santa Cruz. Vol. II, España, Milenio Ediciones y Alfa Centro Editor.

CÁCERES, A. P. y GARCÍA, A. N. (2004). Diferenciación Interna del Espacio Geográfico de Río Gallegos: Estudio Preliminar. Revista del Instituto de Investigaciones Geográficas de la Patagonia. IGEOPAT. Año III. N N 3. UNP. páginas. 11-36. Comodoro Rivadavia. Chubut.

CÁCERES, A.; SÁENZ, J.; MELGAREJO, G. y AMPUERO, C. (2011). Definición de estratos residenciales en el área Rururbana Intraejidal de Río Gallegos; ciudad intermedia de la Patagonia austral argentina. Ponencia III Congreso Nacional de Departamentos de Geografía de Universidades Públicas. Comisión: 4 La ciudad, objeto de debate. Santa Fe, octubre de 2011.

CÁCERES, A. P.; NORAMBUENA, M.; AMPUERO, C.; TRIVIÑO, G. (2013). "Consolidación de la tercera franja residencial de Río Gallegos, Patagonia Argentina". En Actas Congreso Internacional de Geografía - 74a Semana de Geografía "Geografía, Desarrollo Local y Regional” Trevelin (Chubut). Contribuciones Científicas GÆA | Vol. 25 | Págs. 47-59. ISSN 0328-3194.

CÁCERES, A.; SEGOVIA STANOSS, M.; SOTO J.; NORAMBUENA, M.; FRÍAS, P.; AMPUERO, C. (2016). Posición Geográfica de Río Gallegos en la Patagonia Austral”. Congreso Internacional de Geografía. $77^{a}$ Semana de Geografía "Geografía del Bicentenario". San Miguel de Tucumán (Tucumán). Actas. Páginas. 47- 60. 14 páginas.

CACERES, A.; NORAMBUENA, M.; FRIAS, P.; AMPUERO, C. (2017). Nueva Área Rururbana Intraejidal de Río Gallegos: Barrios incorporados en el siglo XXI. Universidad Nacional de la Patagonia Austral, Unidad Académica Río Gallegos (UNPA - UARG). Instituto de Ciencias del Ambiente, Sustentabilidad y Recursos Naturales (ICASUR) - Grupo Z Terra Cognita.

CÁCERES, A. P. (2019). Subdivisión interna de la Segunda Franja Residencial de Río Gallegos. Inédito.

CÁCERES, A. P. (2021). Delimitación de la Cuarta Franja Residencial del ejido municipal de Río Gallegos. Inédito

CÁCERES, A. P. (2021). Actualización de la Tercera Franja Residencial de Río Gallegos del ejido municipal de Río Gallegos en 2021. Inédito

CARBALLO, C. y FLORES, F. Compiladores (2019). Geografías de lo sagrado en la contemporaneidad. 1ra edición - Bernal, Universidad Nacional de Quilmes. Libro digital, PDF Archivo Digital: descarga ISBN 978-987-558-569-0.

CARBONELli, M. A.; MOSQUEIRA, M. A. (2008), "Luis Palau en Argentina": Construcción mediática del cuerpo evangélico, disputa por el espacio público y nuevas formas de territorialidad". 
CLAVAL, P. (2000). Los fundamentos de la geografía cultural. Doc. Anál. Geogr. 34. Páginas 25-40.

CLAVAL, P. (2006). The Cultural approach in Geography. Practices and Narratives. Páginas 16-22. Descargado el 27 de marzo de 2021

DECRETO 297/2020. Descargado el 23 de abril de 2021. En: https://www.boletinoficial.gob.ar/detalleAviso/primera/227042/20200320

DECRETO N ${ }^{\circ}$ 0273/2020 Ejecutivo Provincia de Santa Cruz. Descargado el 23 de abril de 2021. En: https://www.santacruz.gob.ar/boletin-oficial/category/267-marzo$2020 \#$ gsc.tab $=0$

DECRETO $\mathrm{N}^{\circ}$ 891/20 Ejecutivo Municipal Ad Referéndum del HCD Río Gallegos. Descargado el 23 de abril de 2021. En: https://hcdrg.gob.ar/2020/04/03/concejalesaprobaron-la- emergencia-sanitaria-comercial-y-economica-en-rio-gallegos/

FIANI, D. (2011). Dinámicas del crecimiento pentecostal en la ciudad de Río de Janeiro. El caso de la Iglesia Universal del Reino de Dios. Universidade Federal do Rio de Janeiro. Brasil. Disponible en pdf.

FLORES, F. C. (2012). Luján como hierópolis: del relato espacial al lugar religioso. Revista Universitaria de Geografía. Vol. 21, 2012, pp. 137-158 Universidad Nacional del Sur Bahía Blanca, Argentina.

GONZÁLEZ, C. y CÁCERES, A. P. (2018). Determinación del área de influencia del Nodo de Servicios (NS) de la Circunscripción III, Tercera Franja Residencial (TFR) de Río Gallegos. En: ICT-UNPA-180-2018 ISSN: 1852-4516 Aprobado por Resolución N ${ }^{\circ}$ 0709/18- R-UNPA. https://doi.org/10.22305/ict-unpa.v10i2.270

HUENCHOR, F., NORAMBUENA, M., y CÁCERES, A. (2020). Culto Evangélico: Identificación, localización y caracterización en la segunda franja residencial (SFR) de Río Gallegos. Informes Científicos Técnicos - UNPA, 12(1), 122-150. https://doi.org/10.22305/ict-unpa.v12.n1.706

MANCILLA H. (2009), Núcleo formativo del campo evangélico: heterogeneidad identitaria en Río Gallegos (Santa Cruz) hacia fines de 1950. En Actas XII Jornadas Interescuelas/Departamentos de Historia. Departamento de Historia, Facultad de Humanidades y Centro Regional Universitario Bariloche. Universidad Nacional del Comahue, San Carlos de Bariloche. Argentina.

MUNICIPALIDAD DE RÍO GALLEGOS (2012). Departamento de Actividad Parlamentaria, Zonificación. Legislación vigente. Ordenanza No 3259: Reglamentación.

NORAMBUENA, M. (2019). Caracterización de las Denominaciones Evangélicas en Río Gallegos. Inédito.

SANTARELLI S. y CAMPOS, M. (2011), Geografía de las Religiones, Espacios Locales y subjetividad. Una nueva mirada en la enseñanza universitaria. Revista Geográfica de América Central, vol. 2, julio-diciembre, 2011, páginas. 1-19 Universidad Nacional Heredia, Costa Rica.

SHMITE, S. M. y NIN, M. C. (2007). Geografía cultural. Un recorrido teórico a través del diálogo de autores contemporáneos. Revista Huellas Universidad Nacional de La Pampa.

STODDARD, R. y PROROK, C. (2003). Geography of Religion and Belief Systems. Geography. Faculty Publications. Página 263. Descargado el día 27 de marzo de 2021.

WARF, B. y WINSBERG, M. (2008). The Geography of Religious Diversity in the United States. Página 413. Descargado el día 27 de marzo de 2021. https://doi.org/10.1080/00330120802046786

ZUSMAN, P., CASTRO, H. y SOTO M. (2007). Cultural and social geography in Argentina: Precedents and recent trends. Social \& Cultural Geography. Soc. Cult. Geogr. 8. 775798. https://doi.org/10.1080/14649360701633360 